\title{
EL ÁREA DE ENTIERROS HUMANOS DEL SITIO ARQUEOLÓGICO FAMILIA PRIMÓN (CORONDA, SANTA FE): NUEVOS DATOS Y DISCUSIONES PRELIMINARES
}

\author{
HUMAN BURIAL AREA FROM THE FAMILIA PRIMÓN ARCHAEOLOGICAL SITE \\ (CORONDA, SANTA FE): NEW DATA AND PRELIMINARY DISCUSSIONS
}

\author{
Paula Galligani ${ }^{1}$, Fernando Balducci ${ }^{2}$ y Julieta Sartori ${ }^{3}$
}

Recibido 20 abril 2020. Aceptado 30 agosto 2020

\begin{abstract}
Resumen: El sitio arqueológico Familia Primón (FP) se localiza en un barrio residencial al sur de la ciudad de Coronda, sobre la margen derecha del río homónimo (departamento San Jerónimo, provincia de Santa Fe). Durante las tareas arqueológicas llevadas a cabo en diferentes momentos se excavaron tres sectores, de los cuales el sector 1 corresponde a un área de entierros múltiples. En este trabajo se presentan los resultados de la reconstrucción de la planta de entierros - lograda a partir de la digitalización de planillas y fotografías recuperadas en formato analógico y su manejo mediante sistemas de información geográfica (SIG) - y de los análisis anatómicos, cuantitativos y tafonómicos llevados a cabo sobre los restos óseos humanos hallados. Adicionalmente, se realiza una síntesis de la información disponible para otros sitios con inhumaciones localizados en la zona vinculada con el río Coronda. En general, los datos obtenidos a partir de la gestión de la información recolectada y de los análisis efectuados indican que en el sitio FP fueron inhumados al menos 18 individuos, tanto en entierros primarios como secundarios, con diferentes orientaciones y características comparables con las relevadas en otros sitios del área y también de la región del Nordeste argentino.

Palabras Clave: arqueología, entierros humanos, Coronda, Nordeste argentino, SIG.
\end{abstract}

\begin{abstract}
Familia Primón (FP) is an archaeological site located in a residential area in the south of Coronda city, on the right bank of the homonymous river (San Jerónimo department, Santa Fe province). During the archaeological fields works carried out, three sectors were excavated; sector 1 corresponds to a multiple human burial area. This paper presents the results of the reconstruction of the burial map - achieved from the digitalization of the spreadsheets and photographs recovery in analogical format and their management through geographic information systems (GIS) — and from anatomical, quantitative and taphonomic studies carried out on the human bone remains. Additionally, a synthesis of available information of other sites with human burials located in the area of the Coronda River is made. In general, the results show that at least 18 individuals were buried at the FP site, both in primary and secondary burials, with different orientations and characteristics comparable to those relieved from other archaeological sites in the area and also in the Northeastern of Argentina.
\end{abstract}

Keywords: archaeology, human burials, Coronda, Northeast Argentina, GIS.

\section{Introducción}

Las primeras investigaciones de carácter arqueológico realizadas en el Nordeste argentino surgieron hacia finales del siglo XIX y principios del XX, momento en el cual las perspectivas histórico-culturales, dominantes en la región, provocaron que los trabajos se enfoquen en la clasificación y asignación de los contextos arqueológicos a una cultura particular. Principalmente las características de la alfarería, aunque también ciertos atributos asignables a los entierros humanos (e.g. entierros en urnas), fueron utilizados como un rasgo distintivo en la definición de aquellas culturas (e.g. Outes, 1918; Serrano, 1931; Torres, 1911). Con el correr de las décadas, los estudios arqueológicos en general, y aquellos vinculados con las prácticas mortuorias en particular, comenzaron a sistematizarse y a enfocarse desde otras perspectivas (e.g. bioarqueológicas, bioculturales) (e.g. Cornero, 1999; Kozameh \& Barboza, 1999; Mazza \& Loponte, 2012; Scabuzzo \& Ramos Van Raap, 2017).

Específicamente en la zona de la cuenca del río Coronda, los sitios arqueológicos con presencia de inhumaciones son escasos. En el sector insular, los yacimientos que presentan este tipo de registro son Las Tejas, Pajas Blancas, Isleta del Árbol Viejo y Los Bañados; mientras que en la margen derecha de dicho río sólo se identificaron, hasta el momento, tres sitios con entierros humanos: Río Salado-Coronda II, Campo Cervi y Familia Primón. Este último, motivo de esta comunicación, se ubica al sur

1 División Antropología, Facultad de Ciencias Naturales y Museo, Universidad Nacional de La Plata; CONICET; Grupo de Investigaciones Arqueológicas del Nordeste (GIAN); Fundación Arqueológica del Litoral (FUNDARQ); Paseo del Bosque s/n (1900) La Plata, Buenos Aires - paulagalligani@hotmail.com

2 Instituto de Arqueología, Facultad de Filosofía y Letras, Universidad de Buenos Aires; CONICET; Grupo de Investigaciones Arqueológicas del Nordeste (GIAN); Fundación Arqueológica del Litoral (FUNDARQ); 25 de Mayo 217 (1002) CABA - ferbalducci@ gmail.com

3 Laboratorio de Sedimentología-Geomorfología Fluvial, Facultad de Ingeniería y Ciencias Hídricas, Universidad Nacional del Litoral; CONICET; Grupo de Investigaciones Arqueológicas del Nordeste (GIAN); Fundación Arqueológica del Litoral (FUNDARQ); CC 217 (3000) Santa Fe, Santa Fe - julisartori@gmail.com 
de la ciudad de Coronda (departamento San Jerónimo, Santa Fe) y fue excavado en varias oportunidades desde el año 2004, diferenciándose tres sectores, uno de los cuales corresponde a un área de entierros múltiples. En esta área fueron efectuadas tareas de rescate arqueológico en 2004 por el equipo a cargo del Lic. Cocco, hallándose restos óseos humanos y también especímenes arqueofaunísticos, tiestos cerámicos y materiales líticos (Cocco, Feuillet Terzaghi \& Campagnolo, 2009; Feuillet Terzaghi, Casal, Campagnolo \& Cocco, 2007). En los años 2013 y 2014, luego de casi una década desde de las primeras intervenciones y en el marco del proyecto de investigación de una de las autoras (JS), se llevaron a cabo nuevas excavaciones en el sitio - dado que las construcciones y el poblamiento del barrio se hicieron cada vez más intensos y comenzaron a aflorar en superficie nuevos materiales arqueológicos - aunque no se hallaron nuevas inhumaciones.

Paralelamente, como parte del proyecto doctoral "Modelos de Preservación Ósea Diferencial en la cuenca Fluvial SaladoCoronda (provincia de Santa Fe): Tafonomía Regional en Perspectiva Arqueológica" se propuso el análisis de los restos óseos humanos recuperados en las excavaciones del año 2004 y - gracias a la gentileza de los museos municipales de Santo Tomé (Museo Arqueológico de Santo Tomé-MAST) y Coronda (Museo Municipal José Manuel Maciel) — se pudo acceder a los materiales recuperados en ese entonces, así como también a las planillas e ilustraciones de campo generadas en esas primeras intervenciones al sitio. Estas gestiones permitieron que se continúe con la limpieza de los restos, el análisis y su posterior acondicionamiento y almacenaje, que se describirán en este trabajo.

Por lo tanto, el objetivo de esta comunicación es presentar los resultados de la reconstrucción de la planta de entierros del sitio Familia Primón (FP), lograda a partir de la utilización de sistemas de información geográfica (SIG), y de los análisis anatómicos, cuantitativos y tafonómicos llevados a cabo sobre los restos óseos humanos. Previamente, se realiza una síntesis de la información disponible sobre los sitios arqueológicos con inhumaciones localizados en la cuenca del río Coronda, para luego poder discutir los resultados obtenidos desde una escala más amplia, en vinculación con ésta y otras áreas del Nordeste argentino.

\section{Antecedentes de sitios con entierros humanos en el río Coronda}

Desde comienzos del siglo pasado, en la zona vinculada con el río y la laguna Coronda se han hallado diversos sitios arqueológicos con presencia de entierros humanos, principalmente en el área insular (e.g. Badano, 1940; Serrano, 1922; Zapata Gollán, 1942 en Feuillet Terzaghi \& Escudero, 2010), los cuales se incrementaron durante los últimos 15 años, gracias al desarrollo de nuevos proyectos de investigación en la zona (Feuillet Terzaghi, 2009; Galligani, 2019; Sartori, 2013).

Uno de los sitios emblemáticos de la región es Las Tejas (LT), el cual fue excavado por primera vez por Serrano (1922) y luego contó con sucesivas intervenciones por parte de diversos investigadores (FUNDARQ, 1995; Sartori, 2015). Este sitio data de $1014 \pm 45$ años radiocarbónicos AP (Sartori, 2013) y fue considerado, desde un primer momento, como "cementerio", debido a la presencia de restos humanos (Serrano, 1922). Una característica que se destaca es que los restos óseos hallados en 1995 presentan adherencias de ocre rojo y naranja, a pesar de haberse hallado en el sector de playa, a escasos metros de la superficie (Galligani 2019).

Otro de los sitios del sector insular, Pajas Blancas (PB), también cuenta con inhumaciones y fue trabajado en múltiples oportunidades y por diferentes investigadores (Badano, 1940; Serrano, 1955; Zapata Gollán, 1942 en Feuillet Terzaghi \& Escudero, 2010). En las primeras intervenciones se recuperaron vasijas, de las cuales se destaca una urna funeraria polícroma decorada con pintura roja sobre fondo blanco, dentro de la cual se halló restos de un esqueleto (Badano, 1940). Posteriormente, se recuperaron restos óseos humanos en las últimas excavaciones realizadas por Sartori (2010) y por Bonomo, Costa Angrizani, Torino, Álvarez \& Moreira (2019); este sitio se ubica temporalmente entre los $650 \pm 70$ y $506 \pm 43$ años AP, fechados obtenidos a partir de una muestra de carbón y huesos humanos (Bonomo, Politis \& Castro, 2010; Sartori, 2013).

Por su parte, en el sitio Los Bañados (LB), ubicado en la laguna Coronda, se recuperaron restos óseos humanos sin una disposición discernible, muchos de ellos recolectados asistemáticamente por un pescador que informó del hallazgo en el año 2014. Por este motivo, y debido a que el acceso al sitio se halla sujeto a los ciclos de inundación y sequía vinculados con la llanura aluvial del río Paraná, no se cuenta con datos precisos respecto de la distribución-disposición del registro óseo, además de que los materiales se hallan muy fragmentados (Galligani, 2019).

El último de los sitios localizados en la llanura aluvial adyacente al río Coronda es Isleta del Árbol Viejo (IAV), ubicado en las cercanías de la localidad Desvío Arijón (Santa $\mathrm{Fe}$ ). En el mismo se recuperaron elementos óseos en superficie, correspondientes a tres individuos: dos entierros primarios en posición decúbito dorsal extendido con orientación N-S y E-O, respectivamente, y un cráneo y fragmentos de costillas y huesos largos sin una disposición discernible (Feuillet Terzaghi, 2009). Este sitio, al igual que LB, no cuenta con fechados radiocarbónicos.

En lo que respecta al sector continental, además de FP, sólo se registraron dos sitios con entierros humanos localizados en la margen derecha del río Coronda: Campo Cervi (CC) y Río SaladoCoronda II (RSCII). El primero se ubica a escasos kilómetros hacia el sur de FP, en zona rural de la localidad de Coronda. En el mismo se identificaron restos óseos correspondientes a tres individuos, uno perteneciente a un probable entierro primario extendido con orientación $\mathrm{O}-\mathrm{E}$, otro a un probable entierro secundario de huesos largos alineados con orientación NESO y un cráneo aislado. En general, los huesos se hallan muy afectados superficial, micro y macroestructuralmente, además de que la disposición de los mismos se vio alterada por la acción de raíces de árboles de eucaliptos, directamente relacionados con los entierros. La preservación también está afectada a nivel ultraestructural, no pudiendo obtenerse aún fechados radiocarbónicos (Galligani, Sartori \& Balducci, 2015; Galligani, 2019).

Por último, el sitio RSCII se localiza en la periferia del área urbana de la ciudad de Santo Tomé y cuenta con un sector de entierros en el cual se identificaron un mínimo de 34 conjuntos óseos, algunos de los cuales corresponden a entierros primarios $(n=9)$ con orientación SSO-NNE y secundarios $(n=$ 6), mayormente dispuestos con orientación NNE-SSO, mientras 
que se hallaron también agrupaciones espacialmente discretas de huesos sin un orden discernible (Galligani, 2013; Galligani, Feuillet Terzaghi \& Barrientos, 2016). Durante la excavación, se registraron espículas de ocre en el sedimento entorno a los entierros y, además, una vasija cerámica colocada boca abajo y con valvas de Diplodon sp. en su interior (Feuillet Terzaghi, 2009). Hasta el presente, el área de entierros de este sitio cuenta con tres fechados radiocarbónicos, que lo ubican entre los 1500 y 1000 años radiocarbónicos AP (Galligani, 2013; Sartori, 2008, 2013).

Un aspecto general de la mayoría de los sitios descriptos es que los restos óseos recuperados presentan graves problemas de preservación, que limitan la posibilidad de realizar análisis bioarqueológicos específicos e incluso, en algunos casos, dataciones y estudios isotópicos. Tanto en sitios insulares en los cuales los materiales se hallan sujetos a los procesos de transporte-reacomodamiento fluvial y a los ciclos de inundación/sequía que caracterizan a la llanura aluvial del río Paraná- como en los sitios de continente - localizados en contextos muy antropizados - los huesos se hallan afectados por agentes y procesos que intervienen en su preservación (ver Galligani, 2019). Por este motivo, la mayoría de estos sitios no cuenta aún con información específica vinculada con aspectos bioarqueológicos (e.g. estimación sexo-etaria, paleopatologías), sino que los análisis realizados hasta el momento estuvieron orientados a establecer los procesos diagenéticos que afectaron, y continúan haciéndolo, a los diferentes conjuntos óseos (ver, por ejemplo, Galligani, 2013, 2019; Galligani, et al. 2015, Galligani, Sartori \& Barrientos 2019; Deluca, Ivarz \& Llacza, 2011).

\section{EI sitio Familia Primón (FP) y su contexto}

El sitio arqueológico FP se ubica al sur de la ciudad de Coronda (centro-este de la provincia de Santa Fe), sobre la margen derecha del río homónimo, en un área semi-urbana en la cual, en los últimos quince años, comenzó a desarrollarse un barrio residencial (Figura 1). El mismo se localiza en una zona de albardones — que posee suelos desarrollados sobre matrices aluviales y relieve ondulado y levemente ondulado-, en la curva de los 15 m.s.n.m. Se emplaza específicamente en un área elevada respecto de la planicie de inundación actual, sobre una pendiente que se extiende hacia la margen del río, lo que permite el establecimiento de asentamientos permanentes, así como también favorece el desarrollo de actividades agrícolas en la zona (Sartori, 2013).

Los agentes modeladores del paisaje que predominan en el área son los procesos de acumulación provocados por la acción eólica y los procesos de erosión y acumulación hídrica vinculados a la extensa red hidrográfica del río Paraná, cuyos ciclos influyen en el río Coronda, que es un cauce secundario del mismo (García, Basile \& Riccardi, 2012). Asimismo, este último río se conforma por un sistema de depresiones lagunares que culminan en un flujo encauzado que concentra los caudales que ingresan desde la margen derecha, desembocando sobre el cauce principal del río Paraná, una vez que atravesó toda su planicie de inundación (García et al., 2012).

El tipo de suelo presente en el sitio se corresponde con el Orden Alfisol, Suborden Udalf, Gran Grupo Hapludalf (psamacuéntico thapto-árgico). En el perfil del mismo se
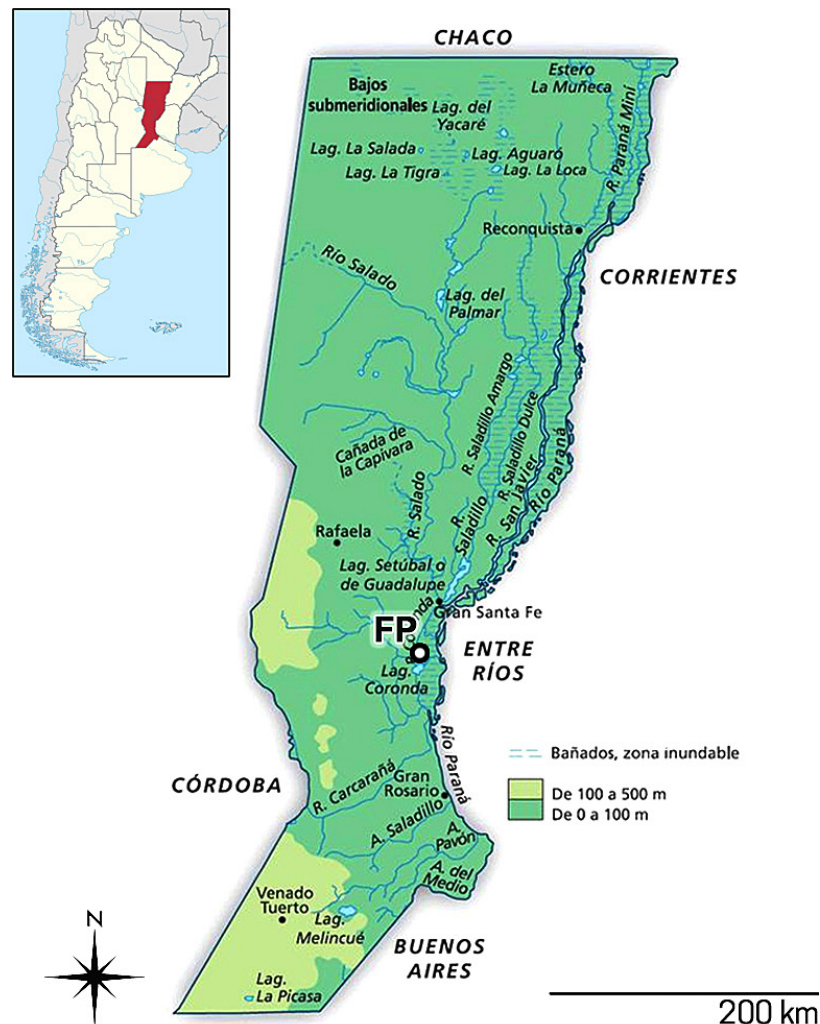

A

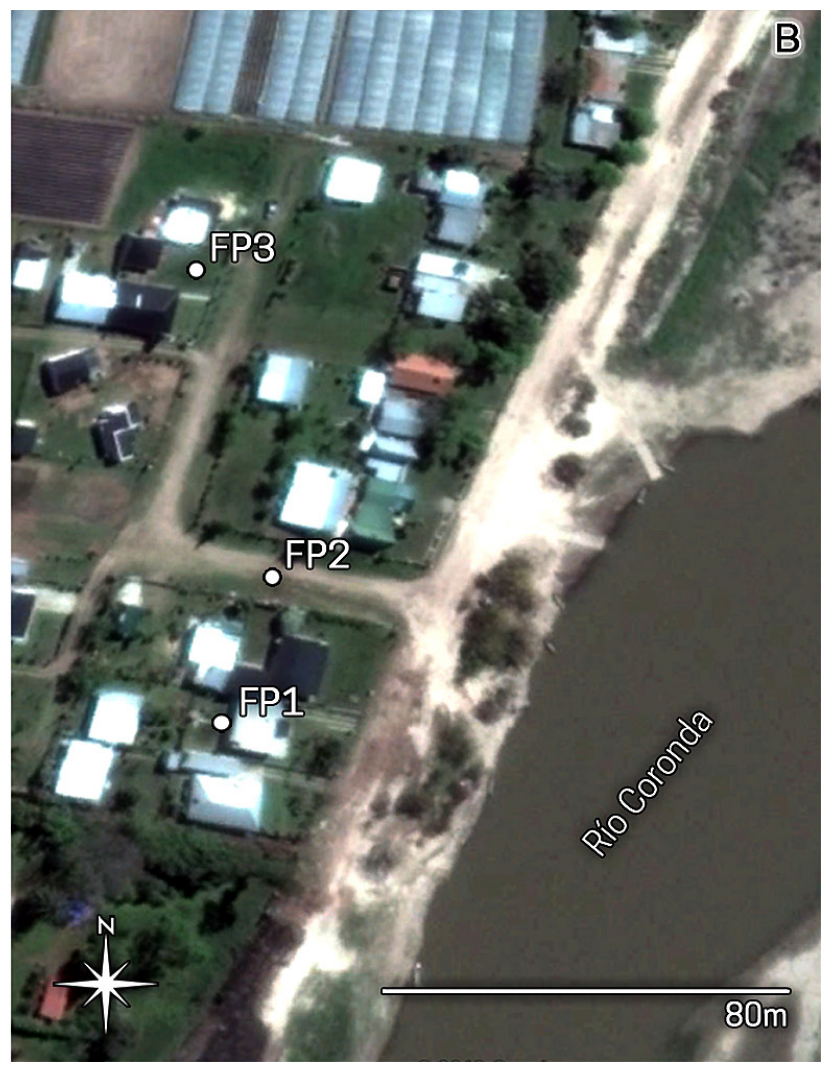

Figura 1. A) localización del sitio Familia Primón en la provincia de Santa Fe; B) ubicación de los tres sectores excavados hasta el momento. 
distingue, entre la superficie y los $24,5 \mathrm{~cm}$ de profundidad, una capa antropizada (Horizonte Ap); luego, entre los 24,5 y 77,5 $\mathrm{cm}$, un Horizonte B, en el cual se diferencia: una capa superior (Horizonte 2B, hasta los 47,5 cm) de color negro parduzco en seco y negro en húmedo, de textura franco-arenosa, bloques subangulares, medios y débiles, de consistencia ligeramente dura a friable en seco y suelta en húmedo, con barnices arcillosos y de materia orgánica abundante; y una capa inferior (Horizonte 2BC) de color pardo oscuro en seco y negro parduzco en húmedo, similar a la anterior pero con agregados granulares (Balducci, Garralla \& Sartori, 2017).

Como se ha mencionado, el sitio fue excavado sistemáticamente en tres oportunidades, en distintos sectores: dos en 2004 , una en 2013 y otra en 2014 (Figura 1B). La primera intervención tuvo lugar durante la remodelación del patio de una vivienda particular del barrio y fue llevada a cabo por el equipo del Lic. Cocco. En aquella oportunidad, se recuperaron restos óseos humanos — que son abordados en esta comunicación— además de fragmentos de cerámica, líticos y restos de fauna, entre los 30 y $100 \mathrm{~cm}$ de profundidad (Feuillet Terzaghi, 2009) (ver más abajo).

A fines de 2013, tras la apertura de una calle a escasos metros del área de entierros (sector 2), quedaron expuestos gran cantidad de materiales arqueológicos. En consecuencia, se realizaron tareas de rescate, planteándose dos cuadrículas y realizándose recolecciones superficiales en un área de seis $\mathrm{m}^{2}$, así como también dos sondeos. En estas intervenciones se hallaron gran cantidad de fragmentos cerámicos (algunos de los cuales son representaciones zoomorfas, mientras que otros presentan incisos, corrugado y pintura roja), líticos y restos faunísticos (Balducci, 2014).

Por último, en febrero de 2014, se realizaron tareas arqueológicas en un predio privado, previas a la construcción de una vivienda particular, en un sector del barrio que se presentó con menor perturbación antrópica que las dos anteriores. Se trazaron cuatro pozos de sondeo y se plantearon dos cuadrículas, de las cuales se extrajo abundante material cerámico y faunístico y escasos ítems líticos, concentrados, fundamentalmente, entre los 25 y $55 \mathrm{~cm}$ de profundidad (Balducci, 2014).

En general, el sitio cuenta con información publicada tanto de las diferentes excavaciones y análisis preliminares realizados sobre el área de entierros (Cocco et al., 2009; Deluca et al., 2011; Feuillet Terzaghi, 2009), como de análisis sistemáticos llevados a cabo sobre restos arqueofaunísticos (Sartori, 2013; Sartori, Balducci, Galligani \& Vallone, 2020), proxy arqueobotánicos (Balducci, 2014; Balducci et al., 2017; Sartori, Balducci \& Galligani, 2018), materiales cerámicos (Balducci, Galligani \& y Sartori, 2019; Feuillet Terzaghi, 2009; Galligani, Balducci, Sartori \& Riberi, 2018) y también estudios de interés tafonómico (Galligani, Tisocco, Castagnola \& Lancellotti, 2017; Galligani, 2019). Los resultados obtenidos hasta el momento indican que el mismo habría funcionado como un área de actividades múltiples, con un área de entierros delimitada (Feuillet Terzaghi et al., 2007; Feuillet Terzaghi, 2009; Sartori, 2013).

Una particularidad del registro del sitio es la presencia de fragmentos cerámicos con rasgos típicos de la alfarería de contextos Goya-Malabrigo (e.g. campanas, apéndices zoomorfos, surco rítmico) junto con otros tradicionalmente atribuidos a las poblaciones de filiación guaraní (e.g. corrugado, pintura bicrómica roja sobre blanca, unguiculado) (ver Balducci et al., 2019; Feuillet Terzaghi, 2009). En este sentido, FP se constituye en uno de los pocos sitios arqueológicos del tramo medio del río
Paraná que combina estos tipos de registros, lo que representa un desafío para la interpretación de la o las ocupaciones humanas en el mismo.

En cuanto a la cronología, FP cuenta con tres fechados radiocarbónicos: el primero, realizado en el sector 1 - sobre un diente humano encontrado a $70 \mathrm{~cm}$ de profundidad-, arrojó una fecha de $370 \pm 30$ años radiocarbónicos A.P. (UGAMS 02471) (Sartori, 2008; Feuillet Terzaghi, 2009); los dos restantes fueron efectuados en los sectores 2 y 3 del sitio: una de $470 \pm 50$ años radiocarbónicos A.P. (LP-3037) sobre una muestra de sedimentos (Balducci, 2014) y el otro, realizado sobre una tibia de Blastoceros dichotomus, de $374 \pm 24$ años radiocarbónicos A.P. (D-AMS 030252) (Sartori et al., 2020). A las tres edades radiocarbónicas —estadísticamente indistinguibles (g.l. $=2 ; \mathrm{T}=3,35 ; \mathrm{X}^{2}=5,99$; p> 0,05; Calib Rev 7.1) — se las agrupó mediante el cálculo de una media ponderada, que arrojó una edad de $384 \pm 17$ años radiocarbónicos AP, ubicando temporalmente al sitio durante los primeros momentos del contacto indígena-europeo.

\section{El área de inhumaciones}

El sector de entierros del sitio FP fue excavado en dos etapas bajo la dirección del Lic. Cocco — en agosto/septiembre y noviembre del año 2004- En esas dos oportunidades se trazaron un total de ocho cuadrículas de $2 \times 2 \mathrm{~m}$, las cuales fueron excavadas sistemáticamente por niveles artificiales de cinco cm, entre 30 y $100 \mathrm{~cm}$ de profundidad real (Feuillet Terzaghi, 2009). Cabe señalar que un sector del patio de la vivienda ya había sido removido por los propietarios, quienes recién detuvieron las tareas de refacción cuando hallaron un cráneo humano. Por este motivo, la zona se vio alterada y se produjo la pérdida de gran parte de la información contextual, sobre todo en el sector central de las cuadrículas excavadas.

No obstante, las tareas arqueológicas realizadas en ese entonces permitieron recuperar entierros humanos primarios y secundarios, que se hallaron a partir de $\operatorname{los} 30 \mathrm{~cm}$ de profundidad en algunas cuadrículas, mientras que en otras comenzaron a aparecer recién a los $70 \mathrm{~cm}$ (Feuillet Terzaghi et al., 2007). De acuerdo con las fotografías y la información publicada, puede interpretarse que - a pesar de las profundidades variables en relación con el nivel actual de suelo- los restos óseos se hallaron en diferentes estratos del horizonte B del suelo (Galligani, 2019).

Se destaca la presencia de una ofrenda funeraria asociada a uno de los entierros humanos, que consistía en un conjunto de valvas de moluscos (Diplodon sp.) (Feuillet Terzaghi, 2009). Además, se hallaron 761 restos óseos faunísticos, 608 fragmentos cerámicos y cinco elementos líticos, en el mismo sector donde se hallaron las inhumaciones (Feuillet Terzaghi, 2009; Sartori, 2008).

Teniendo en cuenta los plazos convenidos con los propietarios de la vivienda para realizar las tareas de rescate, los elementos óseos humanos fueron extraídos con parte del sedimento que los contenía (Feuillet Terzaghi et al., 2007). Una vez retirados, se enyesaron las bases de los bloques removidos y se cubrieron los elementos óseos expuestos con papel de aluminio y una capa de estopa. Por último, se recubrió todo con papel burbuja y films (Deluca et al., 2011; Feuillet Terzaghi et al., 2007). Los materiales fueron alojados en los depósitos del Museo Etnográfico y Colonial Juan de Garay (Santa Fe) y del Museo Arqueológico de Santo Tomé (Santo Tomé, Santa Fe), hasta su recepción en el laboratorio de este equipo de investigación. 

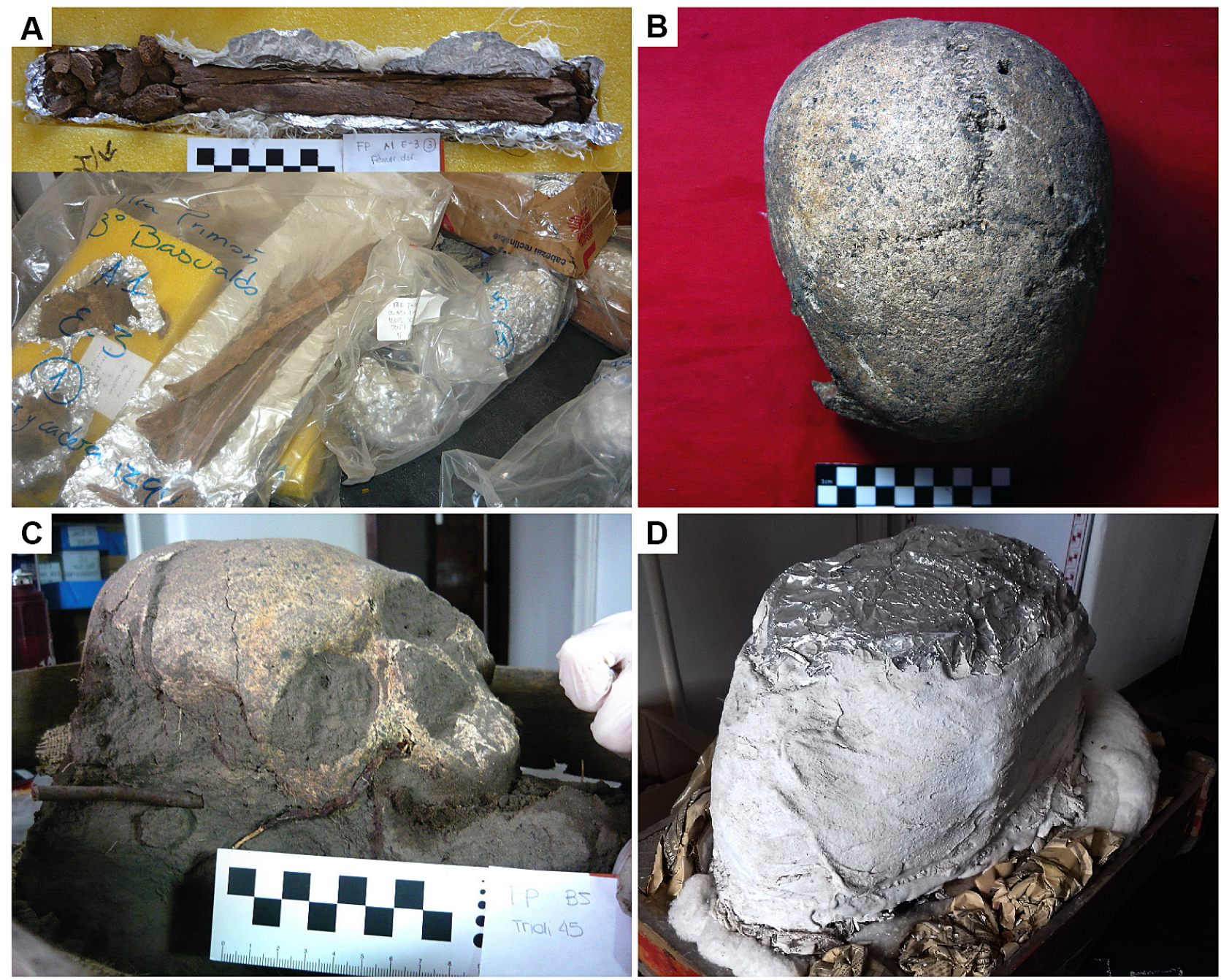

Figura 2. Estado en el que se hallaban los elementos al momento de la llegada al laboratorio. A) completamente limpios y rotulados; B) completamente limpios y consolidados con Paraloid B-72; C) semi-limpios, con parte del sedimento adherido; D) en paquetes compactos consolidados con yeso.

\section{Materiales y métodos}

Los restos óseos analizados en este trabajo corresponden exclusivamente al área de inhumaciones excavada en el año 2004. Además, se accedió a fotografías en formato analógico y a las planillas e ilustraciones de campo (gentileza de la Dra. Feuillet Terzaghi), a la vez que se consultó la bibliografía disponible sobre las excavaciones y los primeros trabajos llevados a cabo sobre el área de entierros del sitio (Cocco et al., 2009; Deluca et al., 2011; Feuillet Terzaghi, 2009; Feuillet Terzaghi et al., 2007).

Por un lado, se llevó a cabo la digitalización y la reconstrucción de la planta del área de entierros, mediante la utilización de sistemas de información geográfica (SIG) y la ayuda de fotografías y trabajos publicados. Toda esta información, utilizada en conjunto, permitió inferir las modalidades de entierro y la distribución de los restos recuperados. Por otro lado, se realizó la limpieza, el acondicionamiento y el análisis anatómico, cuantitativo y tafonómico de los restos óseos, considerando, para el cálculo del número mínimo de individuos (NMI), la información espacial obtenida durante la reconstrucción de la planta. Los análisis mencionados se realizaron en etapas de investigación diferentes, aunque vinculadas entre sí, las cuales se detallan a continuación.

Acondicionamiento, limpieza y almacenamiento de los restos óseos

Luego de la excavación de los entierros, en la bibliografía disponible se detalla que del total de los restos óseos recuperados en FP, se seleccionó sólo una muestra para su limpieza y análisis. La extracción del sedimento adherido (excepto en el caso de los restos con piezas dentales) se realizó mediante la aplicación de acetona por goteo, debido a que, al ser sumamente compacto, su extracción en seco hubiese comprometido la integridad física de los huesos (Deluca et al., 2011; Feuillet Terzaghi, 2009). Además, para conservar la macroestructura de aquellos elementos diagnósticos, dado su grado de fragmentación y friabilidad, se implementaron medidas tendientes a reducir su resquebrajamiento y su proceso de degradación, mediante la aplicación de Paraloid B-72 (Deluca et al., 2011; Feuillet Terzaghi, 2009).

En el momento en el que se accedió a los restos óseos para 
Figura 3. Metodología empleada para la reconstrucción del área de entierros del sitio Familia Primón (FP).

A) planta de excavación publicada (Feuillet Terzaghi, 2009);

B) escaneo y montaje de las ilustraciones de cada cuadrícula excavada;

C) ejemplo de los dibujos de planta de la cuadrícula C5 por cada nivel de excavación;

D) superposición y redibujado de los entierros, a partir de la unión de los diferentes niveles e importación de la imagen rasterizada al proyecto QGIS;

E) digitalización de las planillas de medidas tridimensionales de cada elemento recuperado en hojas de cálculo de Ms. Excel;

F) importación de la localización de los materiales en archivo shape de puntos al proyecto QGIS;

G) ilustración final de los entierros, resultado de la unión de las capas obtenidas y las ilustraciones vectoriales realizadas en el software Adobe Ilustrator.

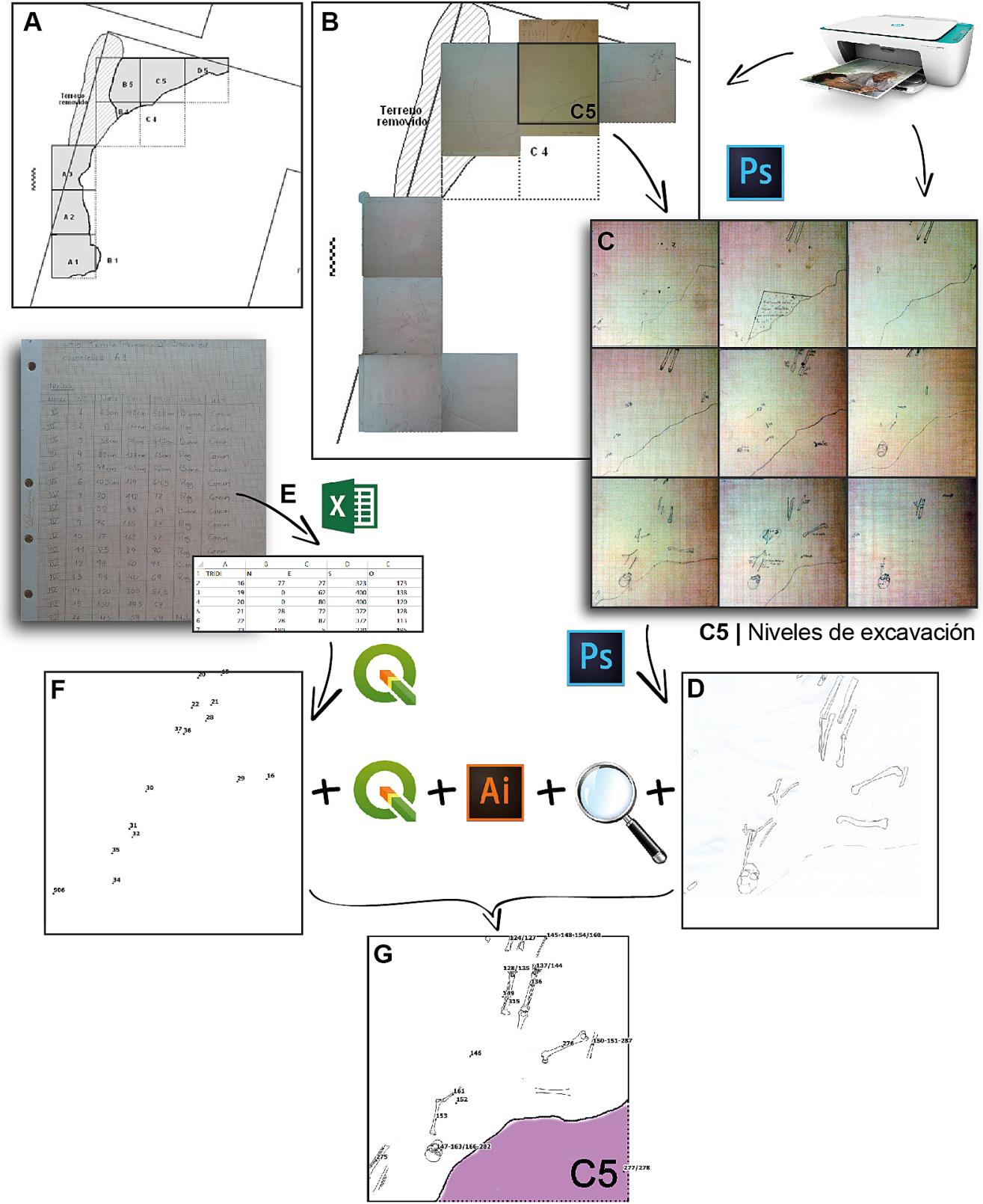

que se recibieron ya acondicionados - en cajas con bases de telgopor, en las que se calaron las formas de los diferentes elementos, de modo que queden fijos y protegidos y no continúen fragmentándose. Cabe señalar que se decidió no aplicar ningún tipo de consolidante a los restos óseos porque aún continúa en discusión si ese tipo de compuestos afecta la extracción de colágeno e interfiere en los resultados de análisis químicos ulteriores (e.g. $\delta^{13} \mathrm{C}, \delta{ }^{15} \mathrm{~N},{ }^{14} \mathrm{C}$ ) (ver discusión en López-Polín, 2012).

\section{Reconstrucción de la planta de entierros}

Para la reconstrucción de la planta de entierros, se realizó la digitalización de los documentos recuperados mediante un escáner Epson Stylus TX125 a 300 ppp. y se utilizaron software de edición de gráficos, tanto en formato raster (Adobe Photoshop CS6) como vectorial (Adobe Illustrator CS6) para redibujar 
las ilustraciones de las plantas de excavación. De este modo, los mapeos de los sucesivos niveles artificiales de excavación (cada cinco $\mathrm{cm}$ ) pudieron superponerse y extraer los bosquejos de los entierros recuperados, los cuales fueron reconstruidos, posteriormente (Figura 3A-D).

En paralelo, se digitalizaron las posiciones de los distintos materiales hallados, de acuerdo a los ejes de cada cuadrícula excavada (Norte y Este), en planillas de cálculo (Microsoft Excel). Estos datos fueron tomados como coordenadas y cargados como capas vectoriales de puntos en un proyecto de sistemas de información geográfica (SIG), específicamente en el software libre QGIS 3.4.10 (Figura 3E-F). Sobre esta capa, se georreferenciaron las imágenes raster de las ilustraciones, mediante la herramienta "georreferenciador", a partir de los vértices de cada cuadrícula. De este modo, y con la ayuda de los análisis anatómicos realizados en forma paralela, se pudo identificar cada elemento relevado tridimensionalmente en los dibujos de planta.

Finalmente, para reconstruir los entierros se utilizaron ilustraciones de acceso libre de esqueletos en formato vectorial, sobre las que se modificaron la posición de los huesos y también se eliminaron aquellos ausentes, considerando — paralelamentelos dibujos de planta, las fotografías obtenidas, la información escrita en las planillas y la identificación anatómica de los elementos óseos recuperados (Figura $3 \mathrm{G}$ ). El único entierro secundario identificado se reconstruyó a partir de figuras de huesos largos que fueron superpuestas de modo que la posición y la orientación coincida con los dibujos originales, las fotografías y las notas de campo.

\section{Análisis anatómicos, cuantitativos y tafonómicos}

En los casos en que el estado de preservación así lo permitió, los elementos óseos se identificaron anatómicamente utilizando colecciones comparativas. Se realizó, asimismo, un análisis cuantitativo, calculando NISP, NME y NMI (Binford, 1984; Lyman, 1994; Mengoni Goñalons, 1999), teniendo en cuenta la localización espacial de los huesos recuperados y sin contabilizar los especímenes indeterminados. Específicamente para el cálculo de NMI, se consideró la ubicación anatómica de los elementos del esqueleto y su vinculación con cada uno de los entierros discretamente identificados. En los casos en que se hallaron elementos dispersos, sin una distribución discernible, se consideraron como acumulaciones óseas y el NMI se calculó para el conjunto discreto de cada unidad de excavación, de acuerdo al elemento más abundante. Asimismo, cuando fue posible la reconstrucción espacial y la identificación de los entierros, se determinó el tipo de inhumación, la posición y la orientación de los mismos, y se relevó la presencia/ausencia de ajuar funerario asociado y la depositación de pigmentos sobre los huesos.

Paralelamente $-\mathrm{y}$ debido a que los huesos se hallaban muy friables y fragmentados- se evaluaron diversas variables postdepositacionales, con el objetivo de caracterizar el estado de preservación del conjunto y los efectos y procesos que intervinieron en el mismo. Se observó la presencia/ausencia de marcas de raíces y roedores, depositación química de carbonato de calcio $\left(\mathrm{CaCO}_{3}\right)$ y dióxido de manganeso $\left(\mathrm{MnO}_{2}\right)$, hoyos de disolución química y craquelado (Barrientos et al., 2007; Galligani, 2019; Gutiérrez, 2004). El relevamiento se realizó de manera macroscópica sobre aquellos elementos identificados que superaron los cinco $\mathrm{cm}$ y, en algunos casos, a través del uso de una lupa trinocular Mikoba 745 de 50X. Por último, se calculó el índice de fragmentación propuesto por Mondini (2003) (NME/ NISP), que varía entre 0 y 1 , para el que aquellos valores cercanos a 1 indican menor fragmentación.

\section{Resultados}

Paralelamente al análisis anatómico y cuantitativo de los restos óseos, y a cotejar los datos existentes en las planillas con las etiquetas presentes en los huesos recuperados, se logró reconstruir la planta de excavación del área de entierros, que se presenta en la Figura 4. La misma se divide en ocho cuadrículas y media (la cuadrícula $\mathrm{C} 5$ se extendió hacia el N, denominándose C6), cuya superficie excavada es de ca. $24 \mathrm{~m}^{2}$. En la figura se puede visualizar claramente que la mayor cantidad de elementos óseos se concentran en el sector norte del área excavada (cuadrículas B5, C5 y D5), zona en la que parte del terreno había sido removido por los propietarios de la vivienda al momento en que informaron del hallazgo de restos óseos.

En cuanto al análisis cuali-cuantitativo, se pudo determinar que la totalidad del conjunto se constituye de un total de 171 elementos anatómicamente identificados, en su mayoría muy fragmentados $(\mathrm{NISP}=2913$; índice de fragmentación $=0,06)$

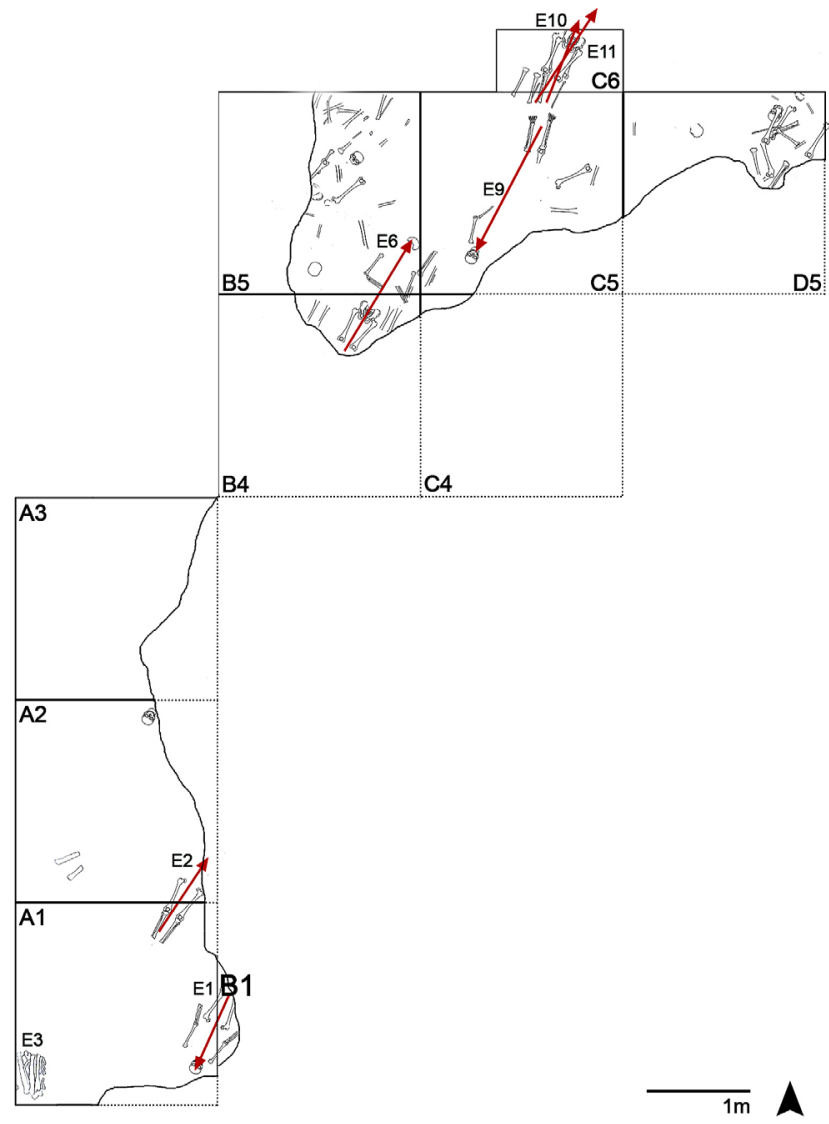

Figura 4. Planta reconstruida del área de entierros del sitio Familia Primón (FP). Se indica el nombre de las cuadrículas excavadas, la identificación de los entierros primarios y del entierro secundario que pudieron ser determinados y en rojo la orientación de los mismos (tomada de Galligani, 2019). 


\begin{tabular}{|c|c|l|c|c|c|c|}
\hline ID & Cuadrícula & \multicolumn{1}{|c|}{ Tipo de entierro } & Orientación & NISP & NME & NMI \\
\hline E1 & A1-B1 & Primario decúbito dorsal extendido & SO-NE & 32 & 14 & 1 \\
\hline E2 & A1-A2 & Primario decúbito dorsal extendido & NE-SO & 59 & 5 & 1 \\
\hline E6 & B4-B5 & Primario decúbito dorsal extendido & NE-SO & 248 & 10 & 1 \\
\hline E9 & C5 & Primario decúbito dorsal extendido & SO-NE & 275 & 28 & 1 \\
\hline E10 & C5-C6 & Primario decúbito dorsal extendido & NE-SO & 180 & 8 & 1 \\
\hline E11 & C5-C6 & Primario decúbito dorsal extendido & NE-SO & 128 & 6 & 1 \\
\hline E3 & A1 & Entierro secundario & N-S & 361 & 17 & 2 \\
\hline 286 & A2 & Cráneo aislado & - & 5 & 1 & 1 \\
\hline E5 & A2 & Acumulaciones óseas & - & 142 & 7 & 1 \\
\hline E7 & B4 & Acumulaciones óseas & - & 61 & 3 & 1 \\
\hline AC. B4-B5 & B4-B5 & Acumulaciones óseas & Total & 2913 & 171 & 18 \\
\hline AC. D5 & D5 & Acumulaciones óseas & Acumulaciones óseas & 273 & 19 & 2 \\
\hline AC. C5 & C5-C6 & & & 150 & 16 & 1 \\
\hline
\end{tabular}

Tabla 1. Detalle de los entierros y acumulaciones óseas recuperados y reconstruidos en el área de inhumaciones del sitio Familia Primón (FP): Cuadrícula de ubicación, tipo de entierro, orientación, NISP (Número de Especímenes Óseos), NME (Número Mínimo de Elementos) y NMI (Número Mínimo de Individuos).

(Tabla 1). En el tafograma se grafican los resultados obtenidos del relevamiento de las diferentes variables tafonómicas (Figura 5). Además de estar muy fragmentados, los huesos de FP se hallan muy afectados por hoyos de disolución química $(51,9 \%)$ y craquelado $(92,4 \%)$. No se registraron marcas de roedores aunque sí una gran presencia de marcas de raíces $(42 \%)$, las cuales dejaron trazas de diferente forma y tamaño, afectando superficial y macroestructuralmente a los huesos. En cuanto a la depositación química, no se evidenció ningún elemento con $\mathrm{CaCO}_{3} \mathrm{y}$, por el contrario, todos los huesos están teñidos —en mayor o menor medida- por $\mathrm{MnO}_{2}$.

Luego de los análisis anatómicos y las correlaciones realizadas, se pudieron identificar seis entierros primarios individuales cuatro con orientación NE-SO y dos con orientación SO-NE-, un entierro secundario múltiple $(\mathrm{NMI}=2)$, con orientación $\mathrm{N}-\mathrm{S}$, un cráneo aislado en la cuadrícula A2 —que posiblemente pertenezca a un entierro que continuaría hacia el noreste, hacia el sector que no fue excavado- y se contabilizaron cinco acumulaciones espaciales de elementos sin un orden discernible, que corresponden a un NMI de nueve (Figura 4; Tabla 1). En total, considerando toda la planta excavada, el número mínimo es de 18 individuos.

Todos los entierros primarios son extendidos, aunque la posición y la orientación son ligeramente variables. En el sector sur (cuadrículas A1-B1 y A2) se hallaron dos entierros primarios: E1 y E2. El primero se trata de un entierro decúbito dorsal extendido con orientación SO-NE, compuesto de 14 elementos óseos identificados, pertenecientes a las extremidades inferiores y superiores, el cráneo y un fragmento de metatarsiano. Por su parte, E2 se halló a un metro de distancia de aquel y corresponde a otro entierro decúbito dorsal extendido, pero con orientación NE-SO y ubicado de manera paralela al anterior. Solo pudieron identificarse cinco elementos correspondientes al mismo: dos fémures, una tibia, un húmero y un radio.

En el sector norte se identificaron otros cuatro entierros primarios. En las cuadrículas B4 y B5, se halló E6, un entierro decúbito dorsal extendido con orientación NE-SO para el que solo se identificaron y correlacionaron 10 huesos largos, muy fragmentados $(\mathrm{NISP}=248)$, aunque en la planta puede interpretarse que el entierro también estaba compuesto por la pelvis y el cráneo. Sin embargo, dado el estado de fragmentación de los elementos recuperados y los procesos postdepositacionales que afectaron al sitio, es probable que el resto de los huesos no se hayan preservado, o bien se hayan dispersado horizontalmente, y se hallen en las acumulaciones de huesos que no están asociadas inmediatamente a este entierro.

En la cuadrícula C5, y su ampliación denominada C6, se pudieron reconocer tres entierros primarios. El entierro E9 se halló en posición decúbito dorsal extendida con orientación SO-NE. En la planta se observa que los elementos que lo componen se hallan dispersos, aunque se puede inferir que corresponden al mismo individuo. Se recuperaron huesos largos de las extremidades superiores e inferiores - muy fragmentados (NISP $=182$ ) y también huesos de las manos y los pies. Hacia el extremo norte de las cuadrículas mencionadas se hallaron, de manera superpuesta, los entierros E10 y E11. Ambos se recuperaron en posición decúbito dorsal extendida con orientación NE-SO y están compuestos por las extremidades inferiores y, en el caso de E10, también por la hemipelvis izquierda. Es probable que la parte superior de ambos esqueletos se halle más hacia el norte, en un sector que no llegó a ser excavado. Asociado a los mismos, se identificó la presencia de un ajuar funerario de valvas de Diplodon sp.

En lo que refiere al cráneo aislado, ubicado en la cuadrícula 


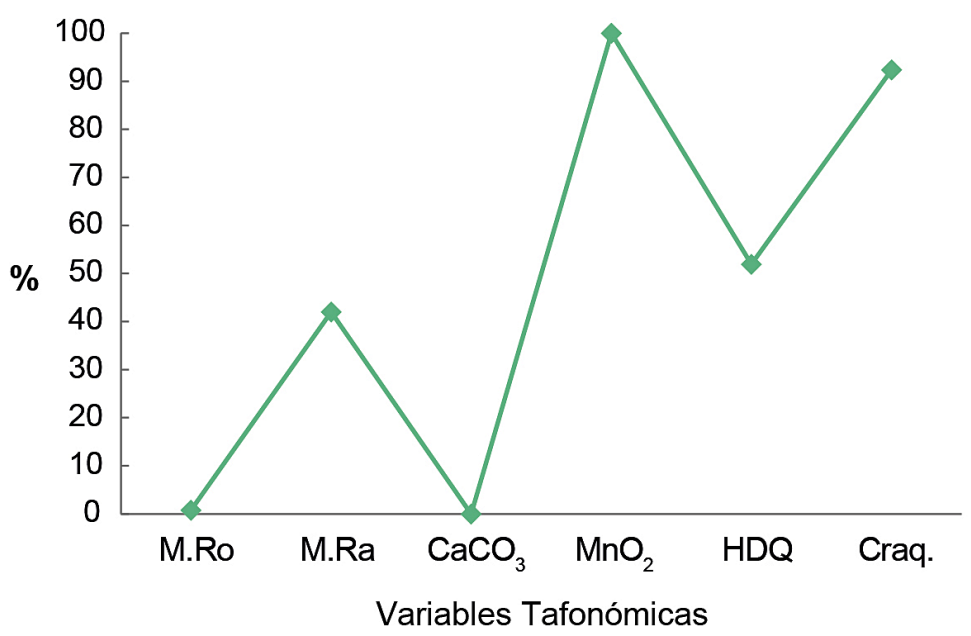

Figura 5. Tafograma que muestra el porcentaje de la presencia de las variables tafonómicas relevadas: $\mathrm{M} . \mathrm{Ro}=$ marcas de roedores; $\mathrm{M} . \mathrm{Ra}=$ marcas de raíces; $\mathrm{HDQ}=$ hoyos de disolución química; $\mathrm{Craq}=$ craquelado.
A2, se documentó de esa forma porque no hay evidencia de relación con ningún otro elemento óseo cercano. Sin embargo, por la posición y orientación de los entierros adyacentes (E1 y E2) - y considerando las menciones que se hacen del mismo al momento de excavación del sitio (Feuillet Terzaghi, 2009)— es probable que corresponda a un entierro primario con orientación SO-NE, cuya porción inferior continuaría hacia el noreste, en el sector que no se continuó excavando.

Por último, también se halló un entierro secundario múltiple (E3), en el que se determinó un número mínimo de dos individuos. El entierro se conforma por 17 elementos identificados, en su mayoría huesos largos alineados con orientación N-S, aunque también se reconocieron fragmentos de costilla, clavícula, omóplato y vértebras. En su totalidad los huesos estaban muy fragmentados $(\mathrm{NISP}=361)$; no se hallaron depositaciones de pigmentos ni ajuar funerario asociado.

\section{Discusión}

Uno de los objetivos de este trabajo, lograr la reconstrucción del área de entierros del sitio FP, pudo cumplimentarse no solo por las ventajas de la utilización de herramientas de digitalización y gestión de información espacial sino también por la minuciosidad y el grado detalle con los que se realizaron las tareas de excavación del área de entierros del sitio FP. Las descripciones y las medidas tomadas al extraer cada resto arqueológico permitieron reconstruir la planta de entierros de un sitio que fue excavado hace más de 15 años, momento en el que los datos fueron relevados totalmente de manera analógica. También el soporte fotográfico es muy detallado y adecuado, a pesar de que, en ese entonces, no se contaba con cámaras digitales. En este sentido, si bien los SIG facilitaron la gestión de la información y, de manera general, abren nuevas posibilidades para el procesamiento de datos, se requiere de un corpus de información de base de calidad para alcanzar el tipo de objetivos propuestos, como es el caso de FP.

Del análisis realizado se desprende que de los siete entierros con posición y orientación claramente identificadas, solo uno corresponde a una inhumación secundaria, ubicada en el extremo sur del área excavada. Este tipo de entierros, a diferencia de los primarios, implica un tratamiento complejo del cadáver, con diferentes etapas que conllevan la eliminación de los tejidos blandos, la desarticulación de los elementos anatómicos y el eventual traslado y reenterramiento de los mismos; asimismo, en algunos casos es común que se aplique algún pigmento (e.g. Schroeder, 2001; Sprague, 2005; Ubelaker, 1999). Específicamente en el área de estudio, Serrano describe este tipo de inhumaciones y expresa que consisten en "desenterrar los cadáveres una vez destruida la carne, barnizar los huesos con ocre y volver a enterrar en la tierra o en urnas" (Serrano, 1922: 64). Si bien en el caso del entierro secundario de FP no se registró la presencia de ningún pigmento, sí se ha evidenciado en el sitio LT, donde se halló ocre color rojo y también naranja adherido a los elementos óseos (FUNDARQ, 1995; Galligani, 2019) y en RSCII donde se describe la presencia de espículas de ocre en torno a los entierros (Feuillet Terzaghi, 2009). Este tipo de registro es mencionado en diversos sitios del Nordeste argentino, como parte de las prácticas mortuorias implicadas en los mismos (Ceruti \& González, 2007; Cornero, 1999; Mazza \& Loponte, 2012; Scabuzzo, Ramos Van Raap, Bonomo \& Politis, 2015).

En cuanto al ajuar funerario hallado, el mismo se compone de valvas de moluscos y se encontró asociado a los entierros primarios 10 y 11, localizados en el sector norte de las cuadrículas C5-C6 (Feuillet Terzaghi, 2009). La vinculación de estas ofrendas con la esfera simbólica ha sido planteada por diversos autores en áreas cercanas como el Delta del río Paraná, la Pampa bonaerense y Uruguay (Acosta, Pastorino, \& Loponte, 2017; Bonomo, 2007; Gascue, Scarabino, Bortolotto, Clavijo \& Capdepont, 2019). Además, este rasgo está presente en otro de los sitios del área del río Coronda (RSCII; Feuillet Terzaghi, 2009) y también en yacimientos del Paraná medio (e.g. Arroyo Arenal 1, La Lechuza, Arroyo Las Mulas, Isla del Indio, Los Tres Cerros 1; Ceruti, Fontana, López\& Vesco, 1980; Cornero, 1999; Pérez Jimeno, 2007; Scabuzzo \& Ramos Van Raap, 2017; Serrano, 1946).

En general, el patrón mortuorio registrado en FP es similar, en cuanto al tipo, posición y orientación de los entierros presentes (entierros primarios extendidos con orientación NE-SO y entierro secundario compuesto principalmente de huesos largos alineados) al patrón regional relevado en el Paraná medio y el Delta (Mazza \& Loponte, 2012; Ramos Van Raap, 2018; Ramos van Raap \& Bonomo, 2016). Los sitios específicamente vinculados al río Coronda no cuentan con información comparable, excepto en el 
caso de RSCII, cuyo patrón de inhumaciones y ajuar funerario es también similar al hallado en FP (Galligani, 2013; Galligani, Feuillet Terzaghi \& Barrientos, 2016). El otro sitio de la zona localizado en continente (CC) se emplaza en un ámbito semirural y se vio muy afectado por procesos postdepositacionales que influyeron tanto en la preservación de los restos óseos como en su contexto de depositación, lo que impidió obtener información contextual de los entierros (Galligani et al., 2015). Sin embargo, el probable entierro secundario hallado entre las raíces de un árbol de eucalipto, está compuesto por huesos largos alineados con orientación NE-SO, ambas características comparables con FP y con otros sitios de la región.

En el caso de los sitios emplazados en el sector de islas (LB, LT, IAV), no se cuenta con suficiente información contextual ya que los elementos óseos recuperados provienen de recolecciones superficiales y de hallazgos fortuitos realizados por pescadores de la zona. Sin embargo, en el caso del sitio LT, como ya se mencionó, se identificó ocre rojo y naranja adherido a los huesos, lo que permite pensar en la presencia de al menos una inhumación probablemente secundaria (Galligani, 2019); y en el sitio IAV se identificó la disposición de dos de los entierros recuperados, los cuales correspondían a inhumaciones primarias en posición decúbito dorsal extendido, una con orientación N-S y otra E-O (Feuillet Terzaghi, 2009). Si bien estas orientaciones no son las mismas que las halladas en FP, la información disponible para IAV debe tomarse con recaudos ya que es incipiente. Asimismo, la dinámica de los contextos insulares debe ser estudiada en profundidad para evitar interpretaciones erróneas de los contextos de inhumación.

Por otro lado, en FP no se hallaron entierros flexionados ni en urnas, modalidad, esta última, que refiere a una práctica inhumatoria vinculada con contextos arqueológicos guaraníes (Ambrosetti, 1895; Loponte \& Acosta, 2013; Ramos van Raap \& Bonomo, 2016, entre otros). En este sentido, si bien se recuperaron tiestos cerámicos en el sector de entierros de FP algunos de ellos asignables a la unidad arqueológica guaraní-, éstos no pueden asociarse de manera directa a un uso funerario, ni tampoco se han hallado concentraciones óseas que sugieran este tipo de prácticas. Además, se ha registrado la presencia de otros materiales arqueológicos (e.g. restos arqueofaunísticos, elementos líticos) esparcidos junto a los entierros humanos (Feuillet Terzaghi, 2009). En este punto, también resulta complejo discernir si los mismos se hallan allí por cuestiones intencionales, vinculadas a las prácticas funerarias, o bien que el sector ha sido utilizado, en ciertas ocasiones, para actividades domésticas. Esta distinción se torna aún más compleja debido a los efectos que han sufrido los materiales arqueológicos por la acción de procesos postdepositacionales, dentro de los cuales se destaca la gran dispersión espacial, vertical y horizontal.

También es necesario aclarar que si bien hasta el momento se registró como "acumulaciones óseas" a los conjuntos de huesos sin una disposición clara, es posible que las mismas sean consecuencia de procesos de dispersión espacial de los huesos. Las mismas prácticas inhumatorias, que implican la reutilización recurrente de un mismo espacio mortuorio, pueden ocasionar la dispersión de los elementos óseos y alterar de diversas formas a los entierros primarios o secundarios previamente depositados (e.g. Galligani, 2013; Scabuzzo \& Ramos van Raap, 2017). A su vez, en el caso de FP, la fragmentación y movimiento vertical y horizontal de los elementos óseos también puede haber ocurrido como consecuencia de diversos agentes postdepositacionales identificables en el mismo (e.g. raíces de árboles de gran tamaño, actividades antrópicas actuales). Se destaca, aquí, el hecho de que parte de los entierros pueden haber sufrido un proceso de extravío y/o destrucción de elementos — total o parcial— durante la remoción de sedimentos realizada para la construcción de la vivienda, al momento en que los propietarios informaron del hallazgo. En este sentido, se están comenzando a realizar análisis espaciales que permitirán interpretar la distribución de los huesos e identificar si las acumulaciones mencionadas no se tratan, en realidad, de entierros primarios que han sufrido los efectos de la dispersión horizontal y vertical de elementos.

En síntesis, los datos relevados en campo acerca del contexto y los diversos estudios tafonómicos realizados sobre los huesos indican que los restos óseos del sitio FP sufrieron los efectos de un conjunto de agentes y procesos postdepositacionales, que no sólo los afectaron macroscópicamente sino también a nivel micro y nanoestructural (ver Galligani, 2019). Las superficies de los mismos se ven muy afectadas por los procesos de disolución química, que en muchos casos modifica hasta la forma de los elementos, y también se hallan muy craqueladas; ambas variables impiden la visualización de huellas y el análisis específico de atributos que podrían informar acerca del estado de salud del conjunto u otras preguntas de interés bioarqueológico. Asimismo, las marcas de raíces y la acción mecánica de las mismas sobre huesos diagenéticamente alterados, sumado a la ausencia de carbonato en los perfiles de suelo - que no contribuyó a la estabilización de la estructura ósea a largo plazo (Gutierrez 2004; White \& Hannus, 1983) - provocaron que incluso durante los procesos tréficos (i.e. aquellos vinculados con el acondicionamiento, almacenamiento y análisis, sensu Clark \& Kietzke, 1967; Hesse \& Wapnish, 1985) se generaran nuevas fracturas. Por último, en lo que refiere a la preservación ultraestructural, varias muestras enviadas para la realización de análisis isotópicos no arrojaron resultados por falta de colágeno (Deluca et al., 2011; Feuillet Terzaghi, 2009) o por la mala preservación del mismo (Galligani, 2019).

Sin embargo, a pesar de los obstáculos y dificultades descriptas, se destaca el hecho de que, luego de 15 años de la excavación original, se pudo acceder a los materiales hallados en ese entonces, al registro escrito y fotográfico y se logró, finalmente, la reconstrucción de la planta de entierros y el análisis anatómico, tafonómico y cuantitativo del total de elementos presentes. Esto permitió aseverar los tipos de entierros y orientaciones presentes en el sitio, así como también lograr una estimación de la cantidad mínima de individuos inhumados. Si bien incipiente, la obtención de este tipo de información es sumamente necesaria a nivel de sitio, para luego poder realizar inferencias de carácter regional acerca de las prácticas culturales involucradas con el tratamiento de la muerte y, además, comenzar a indagar en cuestiones bioarqueológicas, paleopatológicas, demográficas, entre otras líneas de análisis.

\section{Consideraciones finales}

El avance en el estudio del área de entierros del sitio FP es de significativa importancia arqueológica para un área con escasos sitios con sectores de cementerios discretos y con tal cantidad de individuos enterrados, por lo que los resultados obtenidos aportan información valiosa para el estudio de los patrones mortuorios regionales. 
Se han llevado a cabo, hasta el momento, estudios de interés tafonómico sobre los restos recuperados y se culminó con el análisis anatómico y cuantitativo del total de la colección. Si bien los huesos se hallan muy fragmentados y su preservación micro y ultraestructural se ve bastante afectada, resta continuar con el análisis bioarqueológico y las estimaciones sexo-etáreas del conjunto. Este tipo de abordajes han sido escasos en el área de estudio, en parte por la mala preservación de los restos óseos que se hallan en la mayoría de los sitios arqueológicos. Sin embargo, la información obtenida hasta el momento permitirá comenzar a pensar nuevas estrategias y métodos para abordar el conjunto, constituyendo un desafío para generar nuevos datos que permitan integrar a este, y otros sitios del área, en discusiones regionales.

Finalmente, queremos expresar que, una vez finalizados los análisis propuestos para el futuro inmediato, y en concordancia con las políticas de Patrimonio que se vienen desarrollando en el país en los últimos años, los restos óseos serán alojados en el depósito del Museo Municipal "José Manuel Maciel" de la ciudad de Coronda.

\section{Agradecimientos}

A la Dra. Ma. Rosario Feuillet Terzaghi y al Museo Arqueológico de Santo Tomé (MAST) por brindarnos el acceso a los restos óseos humanos, a las planillas de campo y al material fotográfico disponibles. Al Museo J. M. Maciel (Coronda) por las gestiones institucionales realizadas. A Claudio Ñañez y a toda la comunidad Corondá por alentarnos y colaborar con las investigaciones arqueológicas del área. A la Fundación Arqueológica del Litoral (FUNDARQ), por su apoyo continuo. A las integrantes del equipo de investigación por su colaboración en la limpieza, acondicionamiento y análisis de los materiales.

\section{Bibliografía}

Acosta, A., Pastorino, G. \& Loponte, D. (2017). Registro de moluscos marinos entre cazadores-recolectores del norte de la región pampeana. Comechingonia. Revista de Arqueología, 21(1), 233-259.

Ambrossetti, J.B. (1895). Los cementerios prehistóricos del Alto Paraná (Misiones). Boletín del Instituto Geográfico Argentino, 1, 227-263.

Badano, V. (1940). Piezas enteras de alfarería del Litoral existentes en el museo de Entre Ríos. Notas Arqueológicas II. Memorias del Museo de Entre Ríos, 14, 4-23.

Balducci, F. (2014). Ocupaciones Humanas del Holoceno Tardio: Estudio Arqueopalinológico del Sitio Familia Primón (Provincia de Santa Fe). (Tesis de Licenciatura). Facultad de Humanidades y Artes, Universidad Nacional de Rosario.

Balducci, F., Garralla, S. \& Sartori, J.I. (2017). Condiciones paleoambientales y ocupaciones humanas en el sitio Familia Primón (Coronda, Santa Fe): aportes desde la arqueopalinología. Arqueología, 23(2), 63-80.

Balducci, F., Galligani, P.E. \& Sartori, J.I. (2019). Caracterización del registro cerámico del sitio arqueológico Familia Primón (Coronda, Santa Fe, Argentina): diversidad de líneas de abordaje. Folia Histórica del Nordeste, 34, 91-108.

Barrientos, G., Goñi, R., Zangrando, A., Del Papa, M., García
Guraieb, S., Arregui, M.J. \& Negro, C. (2007). Human taphonomy in southern Patagonia: a view from the Salitroso lake basin (Santa Cruz, Argentina). En M. Gutiérrez, L. Miotti, G. Barrientos, G. Mengoni Goñalons \& M. Salemme (Eds.), Taphonomy and Zooarchaeology in Argentina (pp. 187-201). BAR International Series 1601. Oxford: Archaeopress.

Binford, L. (1984). Faunal Remains from Klasies River Mouth. Orlando: Academic Press.

Bonomo, M. (2007). El uso de los moluscos marinos por los cazadores-recolectores pampeanos. Chungara, Revista de Antropología Chilena, 39(1), 87-102.

Bonomo, M., Politis, G. \& Castro, J.C. (2010). Primeros resultados de las investigaciones arqueológicas en el delta superior del Paraná y su contribución al atlas arqueológico de la provincia de Entre Ríos. Folia Histórica del Nordeste, $18,33-58$.

Bonomo, M., Costa Angrizani, R., Torino, R., Álvarez, M. \& Moreira, G. (2019). Nuevas investigaciones arqueológicas en el sitio Cerro de las Pajas Blancas 1 (Delta Superior del río Paraná, Santa Fe). En Actas del XX Congreso Nacional de Arqueología Argentina, 93-96. Córdoba.

Ceruti, C. \& González, M.I. (2007). Modos de vida vinculados con ambientes acuáticos del Nordeste y Pampa bonaerense de Argentina. Relaciones de la Sociedad Argentina de Antropología, 32, 101-140.

Ceruti, C., Fontana, O., López, L. \& Vesco, C. (1980). Arroyo Arenal 4 (Dpto. La Paz, Pcia. de Entre Ríos): un hallazgo arqueológico poco común. Notas del Museo de Ciencias Naturales y Antropología de Entre Ríos, 2, 1-28.

Clark, J. \& Kietzke, K. (1967). Paleoecology of the lower Nodular Zone, Brule Formation, in the Big Badlands of South Dakota. En J. Clark, J.R. Beerbower \& K. Kietzke (Eds.), Oligocene Sedimentation, Stratigraphy, Paleoecology and Paleoclimatology in the Big Badlands of South Dakota. Fieldiana Geology Memoirs, Vol. 5 (pp. 111-155). Chicago: Field Museum of Natural History.

Cocco, G., Feuillet Terzaghi, M.R. \& Campagnolo, L. (2009). Estudios de Impacto Arqueológico en Sitios Prehistóricos Localizados en Áreas Urbanas en la Provincia de Santa Fe, Argentina. En L. Beovide, C. Erchini \& G. Figueredo (Eds.), La Arqueología Como Profesión: Los primeros 30 años (pp. 547-560). Montevideo: Asociación Uruguaya de Arqueología.

Cornero, S. (1999). Enterratorios Humanos en el Litoral: Sitio La Lechuza, Alejandra, depto. San Javier, Santa Fe. En Actas XII Congreso Nacional de Arqueología Argentina III, 384388. La Plata.

Deluca, S., Ivarz, D. \& Llacza, E. (2011). Conservación y curaduría de materiales óseo humanos procedentes del sitio barrio Basualdo Familia Primón (Coronda, departamento San Jerónimo, provincia de Santa Fe). En S. Escudero, M.R. Feuillet Terzaghi, M.B. Colasurdo \& J.I. Sartori (Eds.), Avances y Perspectivas en la Arqueología del Nordeste (pp. 193-201). Santa Tomé: Municipalidad de Santo Tomé.

Feuillet Terzaghi, M.R. (2009). El Registro Arqueológico del Uso 
del Espacio en la Cuenca Inferior del Río Salado y Superior del Río Coronda, Pcia. de Santa Fe. Argentina. (Tesis Doctoral). Facultad de Humanidades y Artes, Universidad Nacional de Rosario.

Feuillet Terzaghi, M.R. \& Escudero, S. (2010). Viejas y nuevas: evidencias de ocupación humana en el Holoceno tardío en la cuenca inferior del río Salado y superior del río Coronda (provincia de Santa Fe). En M. Berón, L. Luna, M. Bonomo, C. Montalvo, C. Aranda \& M. Carrera Aizpitarte (Eds.), Mamül Mapu: Pasado y Presente Desde la Arqueología Pampeana, tomo II (pp. 59-68). Ayacucho: Libros del Espinillo.

Feuillet Terzaghi, M.R., Casal, D., Campagnolo, L. \& Cocco, G. (2007). Intervención arqueológica en un sitio con enterratorios múltiples en la localidad de Coronda, pcia. de Santa Fe. En C. Bayón, A. Pupio, M. I. González, N. Flegenheimer \& M. M. Frère (Eds.), Arqueología de las Pampas (pp. 95-108). Buenos Aires: Sociedad Argentina de Antropología.

FUNDARQ. (1995). Informe de actividades en el sitio LT. Museo Municipal de Coronda J. Maciel. Manuscrito inédito.

Galligani, P.E. (2013). Tafonomía de los Entierros Humanos del Sitio RSCII. (Tesis de Licenciatura). Facultad de Humanidades y Artes, Universidad Nacional de Rosario.

Galligani, P.E. (2019). Modelos de Preservación Ósea Diferencial en la Cuenca Fluvial Salado-Coronda (Provincia de Santa Fe): Tafonomía Regional en Perspectiva Arqueológica. (Tesis Doctoral). Facultad de Ciencias Naturales y Museo, Universidad Nacional de La Plata.

Galligani, P.E., Sartori, J.I. \& Balducci, F. (2015). Procesos postdepositacionales en restos humanos: el sitio Campo Cervi (cuenca fluvial del río Coronda, centro-este de Santa Fe, Argentina). Comechingonia. Revista de Arqueología, 19(2), 347-357.

Galligani, P.E., Feuillet Terzaghi, M.R. \& Barrientos, G. (2016). Los entierros humanos del sitio Río Salado-Coronda II: una aproximación tafonómica a los procesos de modificación ósea postdepositacional en el centro-este de la provincia de Santa Fe, República Argentina. Intersecciones en Antropología, 17 , 187-200.

Galligani, P.E., Tisocco, A. Castagnola, A. \& Lancellotti, F. (2017). Marcas de raíces en huesos arqueológicos: una clasificación a partir del análisis de los restos humanos del sitio Familia Primón (Coronda, Santa Fe). En Libros de Resúmenes del VIII Congreso de Arqueología de la Región Pampeana, 107-108. Luján.

Galligani, P.E., Balducci, F., Sartori, J.I. \& Riberi, M. (2018). Análisis del registro cerámico desde una perspectiva tafonómica: El caso de los sitios arqueológicos Familia Primón y Los Bañados (centro-este de Santa Fe, Argentina). Mundo de Antes, 12(1), 107-133.

Galligani, P.E., Sartori, J.I. \& Barrientos, G. (2019). Bacterial bioerosion in human and animal bones from subtropical environments (Northern Pampa/Middle Paraná River Basin, República Argentina). Journal of Archaeological Science:
Reports, 25, 561-574.

García, M.L., Basile, P. \& Riccardi, G. (2012). Modelación hidrodinámica de sistema cauce-planicie con celdas amorfas, de tramo del río Paraná Inferior. Ponencia presentada en el I Encuentro de Investigadores en Formación en Recursos Hidricos. Ezeiza.

Gascue, A., Scarabino, F., Bortolotto, N. Clavijo, C. \& Capdepont, I. (2019). El rol de los moluscos en las poblaciones prehispánicas de Uruguay. Comechingonia. Revista de Arqueología, 23(1), 115-152.

Gutiérrez, M. (2004). Análisis Tafonómicos en el Área Interserrana (Provincia de Buenos Aires). (Tesis Doctoral). Facultad de Ciencias Naturales y Museo, Universidad Nacional de La Plata.

Hesse, B. \& Wapnish, P. (1985). Animal Bone Archeology. Washington D.C.: Taraxacum Press.

Kozameh, L. \& Barboza, C. (1999). Reflejos de Eficiencia adaptativa en marcadores dentarios. El caso de tres poblaciones cazadoras-recolectoras habitantes de montículos. En J.M. López Mazz \& M. Sanz (Comp.), Arqueología y Bioantropología de las Tierras Bajas (pp. 127-143). Uruguay: Universidad de la República.

López-Polín, L. (2012). Possible interferences of some conservation treatments with subsequent studies on fossil bones: A conservator's overview. Quaternary international, 275, 120-127.

Loponte, D. \& Acosta, A. (2013). La construcción de la unidad arqueológica guaraní en el extremo meridional de su distribución geográfica. Cuadernos del Instituto Nacional de Antropología y Pensamiento Latinoamericano - Series Especiales, 1(4), 193-235.

Lyman, R. (1994). Vertebrate Taphonomy. Cambridge: University Press.

Mazza, B. \& Loponte, D. (2012). Las prácticas mortuorias en el humedal del Paraná inferior. Revista de Arqueología Iberoamericana, 13, 3-21.

Mengoni Goñalons, G. (1999). Cazadores de Guanaco de la Estepa Patagónica. Buenos Aires: Colección de Tesis Doctorales. Sociedad Argentina de Antropología.

Mondini, M. (2003). Modificaciones óseas por carnívoros en la Puna argentina. Una mirada desde el presente a la formación del registro arqueofaunístico. Mundo de Antes, 3, 87-108.

Outes, F. (1918). Nuevos rastros de la cultura Guaraní en la cuenca del Paraná inferior. Anales de la Sociedad Cientifica Argentina, LXXXV, 153-182.

Pérez Jimeno, L. (2007). Investigaciones Arqueológicas en el Sector Septentrional de la Llanura Aluvial del Paraná -Margen Santafesina-: La Variabilidad del Registro Arqueológico. (Tesis Doctoral). Facultad de Ciencias Naturales y Museo, Universidad Nacional de La Plata.

Ramos Van Raap, M.A. (2018). Caracterización del registro mortuorio de la entidad arqueológica Goya-Malabrigo. En G. Politis \& M. Bonomo (Eds.), Nuevas perspectivas sobre la entidad arqueológica Goya-Malabrigo (pp. 175-199). 
Tandil: Editorial Universitaria de la Universidad Nacional del Centro de la provincia de Buenos Aires.

Ramos Van Raap, M.A. \& Bonomo, M. (2016). Nuevos estudios de la colección bioarqueológica de los sitios Arroyo Malo, El Cerrillo y Arroyo Sarandí (Delta del Paraná). Intersecciones Antropología. Volumen especial, 3, 71-82.

Sartori, J.I. (2008). La Cuenca Inferior del Río Salado: un Desafio Para los Análisis Arqueofaunísticos. (Tesis de Licenciatura). Facultad de Humanidades y Artes, Universidad Nacional de Rosario.

Sartori, J.I. (2010). Primeros resultados del análisis del registro arqueológico del sitio Pajas Blancas. En Actas del XVII Congreso Nacional de Arqueología Argentina, 638-641. Mendoza.

Sartori, J.I. (2013). Variabilidad Arqueofaunística en la Cuenca Media e Inferior del Río Coronda. (Tesis Doctoral). Facultad de Humanidades y Artes, Universidad Nacional de Rosario.

Sartori, J.I. (2015). Pasado y presente de las investigaciones Arqueológicas en el sitio Las Tejas (Santa Fe, Argentina). Revista de Antropología del Museo de Entre Ríos, 1(2), 109120.

Sartori, J.I., Balducci, F. \& Galligani, P. (2018). Primeras evidencias de macrorrestos vegetales en el sitio arqueológico Familia Primón (Santa Fe, Argentina). Revista de Arqueología Iberoamericana, 37, 48-52.

Sartori, J.I., Balducci, F., Galligani, P.E. \& Vallone, E. (2020). Ichtioarchaeology on a site located in the border of the aluvial plain of the Paraná River: Familia Primón case (Santa Fe, Argentina). Archaeological and Anthropological Sciences, 12,80 .

Scabuzzo, C. \& Ramos Van Raap, M.A. (2017). Nuevos resultados de los estudios osteológicos del sitio Los Tres Cerros 1 (Delta Superior del río Paraná). Comechingonia. Revista de Arqueología, 21(2), 201-228.

Scabuzzo, C., Ramos Van Raap, M.A., Bonomo, M. \& Politis, G. (2015). Estudios bioarqueológicos en el sitio Los Tres Cerros 1 (Delta Superior del río Paraná, Entre Ríos, Argentina). Boletim Museo Paranaense Emilio Goeldi, 10, 509-535.

Schroeder, S. (2001). Secondary disposal of the dead: Crosscultural codes. World Cultures, 12, 77-93.

Serrano, A. (1922). Arqueología de Las Tejas (provincia de Santa Fe). Revista Universitaria del Litoral, 12, 15-64.

Serrano, A. (1931). Arqueología del Litoral. Memorias del Museo de Paraná, 4, 4-15.

Serrano, A. (1946). Arqueología del Arroyo Las Mulas, en el noroeste de Entre Ríos. Publicaciones del Instituto de Arqueología, Lingüistica y Folklore "Dr. Pablo Cabrera", 13, 1-118.

Serrano, A. (1955). Los Pueblos y Culturas Indígenas del Litoral. Santa Fe: El Litoral.

Sprague, R. (2005). Burial Terminology: A Guide for Researchers. Oxford: Altamira Press.

Torres, L. (1911). Los primitivos habitantes del Delta del Paraná.
La Plata: Biblioteca Centenaria, IV, Universidad Nacional de La Plata.

Ubelaker, D. (1999). Human Skeletal Remains. Washington D.C.: Taraxacum Press.

White, E.M. y Hannus, L.A. (1983). Chemical weathering of bone in archaeological soils. American Antiquity, 48, 316322. 
